\title{
Implications of Merger \& Acquisition on HR strategies of the Acquiring Indian firms: A Structural Equation Modelling Approach
}

\author{
Effulgence \\ Vol. 17, No. 2 (Special Issue) \\ July - December 2019 \\ Rukmini Devi Institute of Advanced Studies \\ E-mail : effulgence@rdias.ac.in, Website : www.rdias.ac.in \\ http:/ / effulgence.rdias.ac.in/user/default.aspx \\ https:/ / dx.doi.org/10.33601/effulgence.rdias/v17/iSpl2/2019/77-91
}

\author{
Ms. Sanober Khan ${ }^{1}$ \\ Prof. Shashank Mehra
}

\begin{abstract}
Purpose - The main purpose of this paper is to study the impact of Merger and Acquisition (MEA) on HR strategies of the selected IT firms in India. Previous studies have reported relationship of $M E A$ with the individual aspects of human resources strategies i.e. HR policies. Limited research has been done to study impact of MEA on basic advantages gained by the human resources of the organization with respect to overall performance of the organization.

Thus, the aim of the present study is to take an integrated view of these HR aspects : Employee Satisfaction, Training $\mathcal{E}$ Development, and Cultural Issues (HR issues) under the concept of HR strategies and examine the impact of Merger and Acquisition on the strategies implemented by the HR of the acquiring firm to attain MEA performance in future.

Design/methodology/approach - The data used in the study was collected by way of primary and secondary sources from a sample of 400 employees working in the Indian IT firms. For interpretation and analysis of the data authors first applied Confirmatory Factor Analysis for Reliability and Validity of the Scale and further applied Structural Equation Modelling(SEM) to study the impact of MEA on Employee Satisfaction, Training and Development and Cultural Issues.

Findings and implications - The paper reveals that MEA has a significant impact on HR Strategies of the firm viz. training and development, employee satisfaction and cultural issues. The results reveal that MEA has higher impact on cultural issues than on employee satisfaction or training and development. There is minimal effect on training and development.
\end{abstract}

Keywords: Merger \& Acquisition (MEA), Human Resource strategies (HR strategies), Merger E Acquisition performance.

\section{INTRODUCTION}

$\mathrm{n}$ the present era's competitive global
environment, mergers and acquisitions have produced a great deal of interest among companies, leading to significant organizational restructuring of the companies. The alteration of organizations has been credited to external forces like globalization,

1. Research Scholar, Sharda University,

2. Member Team-iGAP, SU, School of Business Studies Sharda University, 
political pressure and to the sophistication of clients. (Yu, Engleman, \& Van de Ven, 2005; Ojanen, Salmi \& Torkkeli, 2008). In response to these multiple kind of pressures, it is critical for organizations to ensure operational flexibility, performance and development. As a result, companies have entered into mergers and acquisitions to increase their competitiveness, survival, shareholder value maximization and efficiency, and to strengthen their brand identity. (Appelbaum, Gandell, Yortis, Proper \& Jobin 2000; Woodward, Shannon, Cunningham, McIntosh, Lendrum, Rosenbloom, \& Brown 1999).

Merger is a process of combining two companies, thereby forming a new society. An acquisition refers to the process by which a company simply buys another company. Mergers and acquisitions have led to internal restructuring in work processes and structures that include organizational reorganization, information flow, cultures, business policies and leadership style (Schoenberg, 2006; Appelbaum et al. 2000). Restructuring can be defined as "the reconstruction of a strategy, structures and business processes and their coordination with the new reality". To be consistent, a complete change of the entire organizational system is a must to succeed (Allen 2007; Kieselbach et al.2009).

Mergers and Acquisitions (M\&A) can help companies enter new markets, reduce research and development costs and accelerate growth (Jørgensen \& Jørgensen, 2010). M\&A lead to substantial financial benefits $(\mathrm{Yu}$, Engleman, \&Van de Ven, 2005). Fruitful Mergers enable companies to generate higher profits and in turn provide more resources. They can deliver impressive economies of scale. M\&A lead to tax benefits and increase in revenue through market share gains. Mergers and Acquisitions often increase value for the company. It is expected that after M\&A shareholder value of company is greater than the sum of the shareholder values of the parent companies. An increase in market share is one of the credible benefits of M\&A. When a financially strong company acquires a relatively heavy business, the resulting organization can see a significant increase in market share. The new business is more profitable and competitive than its financially weak parent association (Kieselbach et al. 2009). The merger with another company, which includes increasing success, gives the small business the opportunity to grow and continue to deliver products easily. Small business also benefits from the research and finance of the largest company to develop new products. (Rashid \& Naeem, 2017).

HR strategy of an organization integrates the corporate culture, people and system by synchronizing a series of measures to accomplish the required business goals (Sharma \& Mareja, 2016). The closer the coordination between HR and the overall business strategy of a business, the better the company's ability to go ahead and respond to customer needs and improve the competitive advantage (Liu et al., 2017). Laborious research, planning and development on work culture, behaviors and skills encourage the successful implementation of the commercial strategy. HR strategies create the basic parameters for people management at workplace (Vidija, Peter \& Ogutu, 2016). Any Human Resources strategy is determined by the capability and leadership style of local managers to pursue objectives linked to environmental conditions (Purcell 1989).

Amid all the groups within an organization, both functional and professional, human resource department is considered the best to play the main role in the arts and sciences approach to attain organizational sustainability. Human Resource activities enable the organization to appoint qualified, dedicated and motivated employees and sustain the skills of people to improve and develop by providing powerful work opportunities systems. high management practices that recognize employees who are interested and valued in the organization. To help the organization find a balance and holistic participation human resource should ensure people of what they are going to do and achieve, appreciate and reward, the management of 
workforce diversity (Becker et al., 1997; Batt, 2000; Bari, Fanchen \& Baloch, 2016).

To be successful in the corporate world the firm requires to be proactive and prepared for a lively work environment. This is attained through strategic management decisions in case of mergers, which have given noteworthy benefits like efficiency in organizational processes and resources. (Caetano \& Neves, 2006). The benefits and success of the mergers are decided by the effective organizational restructuring by the achievement of the desired objectives of the restructuring. Over the past few years, reports of a fusion failure have been between 45\% and 60\% (Appelbaum et al. 2000; Schoenberg, 2006). The main factor responsible for the failure of such $M$ \& A activities has been lack of the organization, in linking M\&A with the human side.

\section{Gap Identification}

Existing studies have described the relationship of M\&A with individual aspects of HR strategies, i.e HR policies, and further explored their HR outcomes. This link has contributed results towards the HR goals. Therefore, it is needed to understand the integrated view of impact of M\&A on Human Resource Strategies which ultimately leads to the success of that M \&A which has taken place.

\section{Context of the Study}

The present study aims to holistically consider HR aspects, ie employee satisfaction, training \& development and cultural issues under the concept of HR strategies. The study intends to examine the impact of M\&A on the strategies that are implemented by the HR of the acquiring company to achieve M\&A performance in the future. In light of the above the present study attempts to fill the recognized research gap by statistically studying the impact of M\&A on HR strategies

\section{Expected Contribution of the study}

The study can help Personnel Managers identify problems and schedule due diligence, to develop a criterion / template for assessment of employees and the organization in terms of its cultural suitability. On the basis of such a study HR-specific M\&A policies can be developed, training of the deal team can be done on critical change issues at work. HR team can collaborate with Management to determine integration policies and identify candidates for culture as well as implementation issues (Berger, 2009).

In light of the above fact, the present study attempts to fill the recognized research gap by examining the impact of M \& A on HR strategies. The rest of the study is organized as follows. The next section gives a brief overview of the concept of merger and acquisition and outlines the studies that examine the impact of mergers and acquisitions on HR strategies. Thereafter the paper goes on to explains the research methodology, data analysis techniques and their interpretation. Finally, the conclusion of the study is presented.

\section{Merger \& Acquisition}

As per the existing research results of Hirsch \& de Soucey (2006) restructuring is an important strategic effort taken by the organizations to cope with social and economic changes. Generally, the main objective of doing so is adjustment and sustainability in an ever-changing business scenario. The work done by Armstrong \& Stephens (2005) suggests that organizational restructuring is related to transformation and management of existing business units. In the contemporary research studies, "organizational restructuring" has been explained from distinct viewpoints. "Organizational restructuring" is considered to be restructuring of the work processes and the structure of the organization to meet the present and the future requirements along with a planned course of action. Significant results suggest that (Hirsch \& de Soucey, 2006; Storrie\& Ward, 2007) the major cause of restructuring is response to the global changes much 
in advance. The European Monitoring Centre on Change (2011) explained through their work that organizational restructuring includes a variety of forms of change. Among all, delocalization, mergers, acquisitions, outsourcing are the most common ones. Research reflects that organizations have adopted M\&A as forms of restructuring depending on their present circumstances and future goals to be achieved. Merger is a combination of two or more organizations to become a single unit whereas Acquisition is a complete take-over of the assets and shares of one company by the other (Raquib, Musif \&Mohamed 2003). M \& A have been considered as synonymous because both the terms serve similar purpose, i.e. achieving sustainable performance. Hogan and Overmyer-Day (1994) provide evidence that merger associates business assets giving equal control via an agreement and acquisition includes purchasing of business assets of one organization by the other as a complete buyout. The difference between merger and acquisition can be explained by the mode adopted by the firms while collaborating with each other (Roberts, Wallace and Moles 2003). Therefore, due to the evidences of the previous research, M \& A are taken as a substitute of one another in the current study.

\section{Human Resource (HR) Strategies}

HR strategies serve as a guideline for sustainable performance by persuading human capital in timely management of business disputes to achieve the organization's goals (Armstrong 2016). HR strategies enable end-to-end value creation through effective management of human resources in the organization. There are guidelines for the organization that is strived for in the struggle to maintain new and competent resources for growth and progress (Armstrong \& Taylor, 2015). The guidelines are in the form of policies or practices that are designed and adopted by the organization's HR managers to grow employee skills for future opportunities, to generate and link the employer's brand image, to manage individual professional goals, and to manage change in employee mindset in the case of $\mathrm{M}$ \& $\mathrm{A}^{\prime}$ 's (www.ey.com/...role-ofhr...practices / .../EY-Role-of-HR-in-drivingsustainable - Businesses). The HR strategies transfer the beliefs of the organization to its employees. These strategies give a direction for decision-making and the future course of action (Armstrong and Baron, 2002).

The implementation of HR practices is with the intention of retaining existing employees on a large scale (Guthrie, 2001). Evidence from past research thus underlined that the perception of HR practices is strongly related to the creation of employee loyalty in the organization (Tsui et al., 1997). Ostroff and Bowen (2000) also argue that there was a remarkable relationship between HR practices and employee mind-sets. In addition, HR practices have been effective in the global competitive market (Delery and Doty, 1996). However, studies like, Meyer \& Allen (1997); Vandenberg \& Nelson, (1999) in the past reported that HR practices were the source of motivation for employees to remain committed.

Economic aspects within an organization are closely linked to well-defined training, development and communication strategies (HRM practices) aimed at keeping skilled and knowledgeable employees at the workplace (Harel, \& Tzafrir, 1999). Garcia (2005), provided evidence that Training \& Development has been actively linked to employee job satisfaction. Thereafter, DeCenzo \& Robbins (1996); Thang \& Buyens (2008); Thang \& Buyens (2009) argued that technological change-driven education and development helped foster employee skills, attitudes and knowledge, further improving the organization's performance. HRM practices such as training and development have influenced innovative workplace behavior (Knol \& van Linge, 2009, Spiegelaere, de et al., 2012). Bysted \& Jespersen (2013) found that training \& development developed the creative skills of employees and formulated their innovative work habits.

From the above studies, it can thus be determined 
that HR strategies that consist of HR practices aim to identify HR issues and achieve HR outcomes in order to further improve the overall performance of the organization.

\section{Literature Review}

Islam et al (2012), through his study identified the effects of mergers and acquisitions on the morale and psychology of the employees working at the State Bank of Indore. The study created a model for indicating the factors that employees fight against in this process. Factor analysis was used taking all variables within a particular group to be highly correlated among themselves, but relatively low correlations with variables in a different group. The results indicated that a pre-merger task force should be prepared to take the feedback from the employees and make them understand the effects and the benefits of mergers and acquisitions. Employees are fearful of losing their job or stagnation in the job. New policies and practices taken up by the organization acquiring another organization or one company merging with another company are an issue of concern for all. Employee resistance leads to delays in the process and adversely affects the business. Hardly any attention is paid to emotional and psychological aspects of the employees at all levels. The paper suggests that HR has a critical role in maintaining transparency in communication related the need for merger and acquisitions. The findings reflect its effect on working and service conditions of the employees.

Weber, Rachman-Moore \& Tarba (2012) studied the managerial practices in use during the integration process to report the post-merger cross-cultural conflict and to predict M\&A performance. The results of the research of the authors reflect that communication and training and development are the practices that can help in dealing with crosscultural conflict and human resource problems post M\&A. Means, Standard Deviation, CorrelationCoefficient and Regression Analysis have been used for the statistical analysis in the present study. The results indicate that there is a significant difference in the use of Human Resource practices of Acquired/Merged firms. The use of these practices contributes towards the performance of the merged firms.

Clarke \& Salleh (2011) investigated the impact of merger and acquisition on the emotional responses of the Employees. Semi- structured interviews were conducted to gather data 10 months following the merger. The findings of the study prove that the emotional responses of the employees were negatively influenced leading to job dissatisfaction and uncertainty among the employees. Hence it is indicative enough that mergers and acquisitions affect the attitude and behaviour of the employees.

Nikandrou, Papalexandris \& Dimitris (2000) argued that mergers and acquisitions negatively influence employee job satisfaction. Therefore, the study investigates the impact of merger and acquisition on employee attitude. A sample of 177 companies operating in Greece was taken for the purpose of this study. Survey method was used to collect data to understand the perception of the employees in terms of employee relations, perceived uncertainty, tolerance to change and change implementation. The data were presented for its statistical analysis. The primary procedure used for data analysis was multiple regression analysis. The results proved that mergers and acquisitions negatively influenced employee's satisfaction. In future, more empirical studies of this sort are required to see the impact of merger and acquisition on employee satisfaction in various contexts.

Baker (2009) provides insight towards the effects of merger and acquisition on job satisfaction among bank employees. Data were collected from 229 employees working in U.S. banks. A structured questionnaire helped in data from various levels in the bank. The questionnaire consisted of standard scale of job satisfaction and demographic variables. The data were analyzed using Factor Analysis, ANOVA and Multiple Regressions. The results 
indicate that the merger and acquisition was negatively associated with job satisfaction. Employees placed in lower positions experienced a greater level of dissatisfaction with their jobs than those placed in higher positions.

Woodward et al., (1999) examine the effects of merger and acquisition on the hospital staffs work environment. Survey method was used to collect data from 900 hospital employees working at Ontario teaching hospital. The survey instrument consisted of standard scales of work environment. Descriptive Analysis, ANOVA and Logistic Regression were the statistical tools used to investigate the data. The results reflected that merger and acquisition lead to the formation of increased workloads and less support from the co- workers. This resulted in creation of stress and a sense of job dissatisfaction among employees. In future, the data from other set-ups would make clear the findings of this study in a more accurate way.

Probst (2003) argues that even though researches on the effects of organizational restructuring are growing continuously but a large number of these researches are likely to be cross- sectional in nature. They depend widely on self- reported data. Thus, the aim of the study was to use Solomon's four group experimental field research designs to validate the findings of the previous studies. Responses were collected from a sample of 500 employees working in a state agency of Midwestern state. The data were subjected to statistical analysis. Results from the multivariate analysis depict that employees affected by restructuring suffer from lower levels of job security, organizational commitment, job satisfaction and perception of role ambiguity as compared to ones not affected by restructuring. The limitation of this research is that the findings of this study are applicable to the organizations undergoing similar types of restructuring (i.e. workplace restructuring) so generalizability of the results cannot be relied on.

Sanda \& Adjei-Benin (2011) worked to understand the influence of Merger \& Acquisition on employee satisfaction and employee satisfaction's impact on the performance of the merged firm. Questionnaire Method was used to collect primary data from the employees working in a Ghanian mining firm. The results of the statistical analysis indicate that there were prominent changes in the work roles of the employees, leading to job dissatisfaction towards their work. There is high amount of discontentment among employees due to work-pressure and workload making them quit their jobs.It is evident from the results that merging two different firms is a complex task as it may lead to critical HR issues. Future research should work on evaluating these HR issues.

Goyal \& Joshi (2012) worked to measure the level of stress among the employees working in the Bank of Rajasthan before and after merger with the ICICI Bank Ltd. Weighted Average Method and a paired sample T-test were used for the analysis of the study to evaluate the level of stress. The major psychological factors which create stress among bank employees are job insecurity, and the threat of job loss. The cultural factors include technology used at the bank, reporting system, working hours, relationship with the boss and the kind of administration given to the subordinate by its immediate boss. The results indicate that the level of stress was less among the employees before merger and subsequently increased to around $64 \%$ after merger in terms of all the psychological factors making the employees switch over to different jobs elsewhere. All the employees faced a severe difference in the work culture of the bank, Under specific conditions the study aims to contribute significantly to the betterment of the bank employees. It gives recommendations to policy makers, and the managers to take preventive measures while handling any mergers and acquisitions to avoid stress among the employees. In future, more studies of this type should be carried out to examine the effect of pre and post -merger effects on the psychological mindset of the people.

Newman \& Krzystofiak (1993) scrutinize the 
information related to job characteristics, employee job satisfaction and organizational commitment in before and after study of the acquisition of a small bank in the northeastern United States by a larger regional bank. A sample of 108 bank employees before the merger and 49 employees after the merger were collected within a time gap of 6 months comprising of a longitudinal data. Correlation Analysis and ANOVA show that perceived job characteristics, employee job satisfaction and organizational commitment declined after the actual acquisition. In future, a large sample size could be taken to unclog statistical inferences about the actual causality.

Covin et al., (1996) study and examine the effect of merger on employee job satisfaction. A sample of 2845 employees comprising of a segment of a fortune 500 company having annual sale of more than $\$ 10$ billion and performing nearly in 25 states was taken for the study. Regression Analysis was applied employee job satisfaction both within the acquired and the acquiring firm. In future, a pre and postmerger assessment concerning the variations in the attitude and behavior of the employees should be carried out to provide a better understanding of the conclusions drawn from the present study.

Based on the studies listed above the figure below highlights a conceptual model reflecting the impact of Merger and Acquisition on Human Resource (HR) strategies with respect to training and development, employee satisfaction and cultural issues .

Broad Hypothesis: There is a significant impact of a Merger and Acquisition on the HR Strategies of the acquiring firm.

H1: Merger and Acquisition has significant impact on training and development.

H2: Merger and Acquisition has significant impact on Employee Satisfaction.

H3: Merger and Acquisition has significant impact on Cultural Issues of the organization.

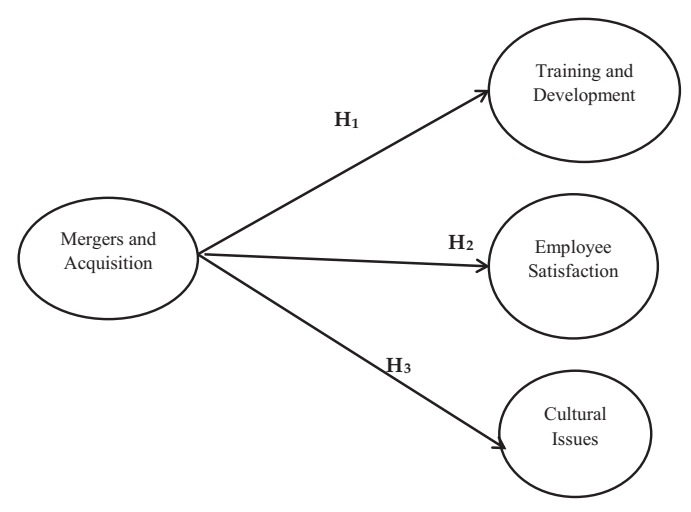

Figure 1: Conceptual Model

\section{Research Methodology \\ Sampling \& Procedure}

Both primary and secondary data have been used to get results against the study objectives. The constructs for Mergers and Acquisition, Training and Development, Employee Satisfaction and Cultural issues have been taken up through review of literature.

In this study, primary data was collected through a structured questionnaire used in retrieving firsthand information from respondents in the Indian IT firms. Multi-stage sampling was used, in the first stage quota sampling has been used to give representation of companies who have gone through mergers and acquisition. From the identified companies random sampling was carried out for the responses of employees. Total 448 questionnaires were distributed to the employees, which reflected their own demographics (e.g. sex and education background), their perception of merger \& acquisition and perceived HR strategies for the chosen dimensions. Considering the incompleteness of some questionnaires 48 responses were excluded as they consisted of missing values. Finally, 400 completed questionnaires were received and included.

\section{Measurement Items}

The reliability and validity were ensured through 
the items in the study used from the measures developed by previous studies.

\section{Section A: Demographic Variables}

This section provides information on employee's demographic characteristics such as gender, age, educational background, length of service and job title respectively. The levels of measurement for this section were in a continuous, interval and numerical forms.

\section{Section B: Constructs}

Satisfaction of merger scale given by Buono Bowditch and Lewis (1985) was used to assess employee's perception of mergers \& acquisitions. This instrument has been widely used in articles and journals as it has been found to be effective in evaluating a person's perception or opinion on merger- acquisition related issues. The Items included have been used by Covin et al. (1996) in their study which yielded a 0.77 alpha value. The reliability coefficient for the scale is 0.79 in a study by Fischer et al. (2007). The scale is in a five-point Likert format ranging from "5-Strongly Agree. to 1Strongly Disagree".

\section{Items for Mergers and Acquisition}

M\&A 1: The M\&A between the concerned firms has taken place.

M\&A 2: The majority of the employees have come to accept the M\&A between the concerned firms as a good idea.

M\&A 3: The Organization has been strengthened by the M\&A between the concerned firms

M\&A 4: The M\&A was well communicated to employees

\section{Items for Employee Satisfaction}

ES1: I feel that there is knowledge transfer of important details to me.

ES2: I agree that I was informed about the size of the team I would work with.

ES3: I feel that there was satisfactory communication of the Job Description related to my position in the Organization.
ES4: Authentic Communication

ES5: I feel that all the shared information is very clear of the purpose which it serves.

\section{Items for Training \& Development}

TD1: I feel that Employees are laid-off from work if performance does not improve after Training and Development.

TD2: I feel that the performance of the employee improves after the Training.

TD3: I feel that my Reporting Boss is satisfied with my performance after the Training.

TD4: I feel that the percentage of time spent in Training is sufficient for appropriate Learning.

TD5: I feel that the Training Sessions lead to my satisfactory Skill development.

TD6: According to me the communication involved in the Training session was appropriate for my understanding.

\section{Items for Cultural Issues}

CI1: I feel that the firm is into Innovation

CI2: I feel that he firm believes in giving attention to details of the business.

CI3: I feel that the firm is ready for Risk - Taking.

CI4: I feel that the firm is highly Outcome - Oriented.

CI5: I feel that the firm is People-Oriented and takes my view-point into consideration.

CI6: I feel that the firm is Team-Oriented and therefore believes in Team work.

CI7: I feel that the work environment is Aggressive.

CI8: I feel that the work environment is Competitive.

\section{Data Analysis and Interpretation}

In the research study structural equation model (SEM) has been carried out in order to evaluate the implication of merger and acquisition on HR strategies. But prior, to conducting SEM confirmatory factor analysis (CFA) has been performed to validate the constructs.

\section{Confirmatory Factor Analysis (CFA)}

In this research work the primary data has been 
collected from the employees in accordance with their perception about the different statements on the selected HR strategies post-merger. In order to analyze the validity of the construct with respect to convergent and discriminant validity, the confirmatory factor analysis has been applied. Confirmatory factor analysis (CFA) checks the construct validity of different factors identified in the study (Hair et al., 1998). The convergent validity of the factors indicates the level to which variables are related to each other and represents the factors. The discriminant validity test checks the level of cross loading of a variable of a factor with the variables of another factor. The convergent validity can be tested through composite reliability statistic and averages variance extracted measure. The composite reliability statistic of each factor is expected to be greater than 0.7. It reflects the level of internal consistency reliability factor. The average variance extracted should be greater than 0.5. It shows the variance in the variables which can be explained by the extracted factors. The average variance extracted of each factor should be greater than its average shared variance as well as maximum shared variance (Hair et al 1998).

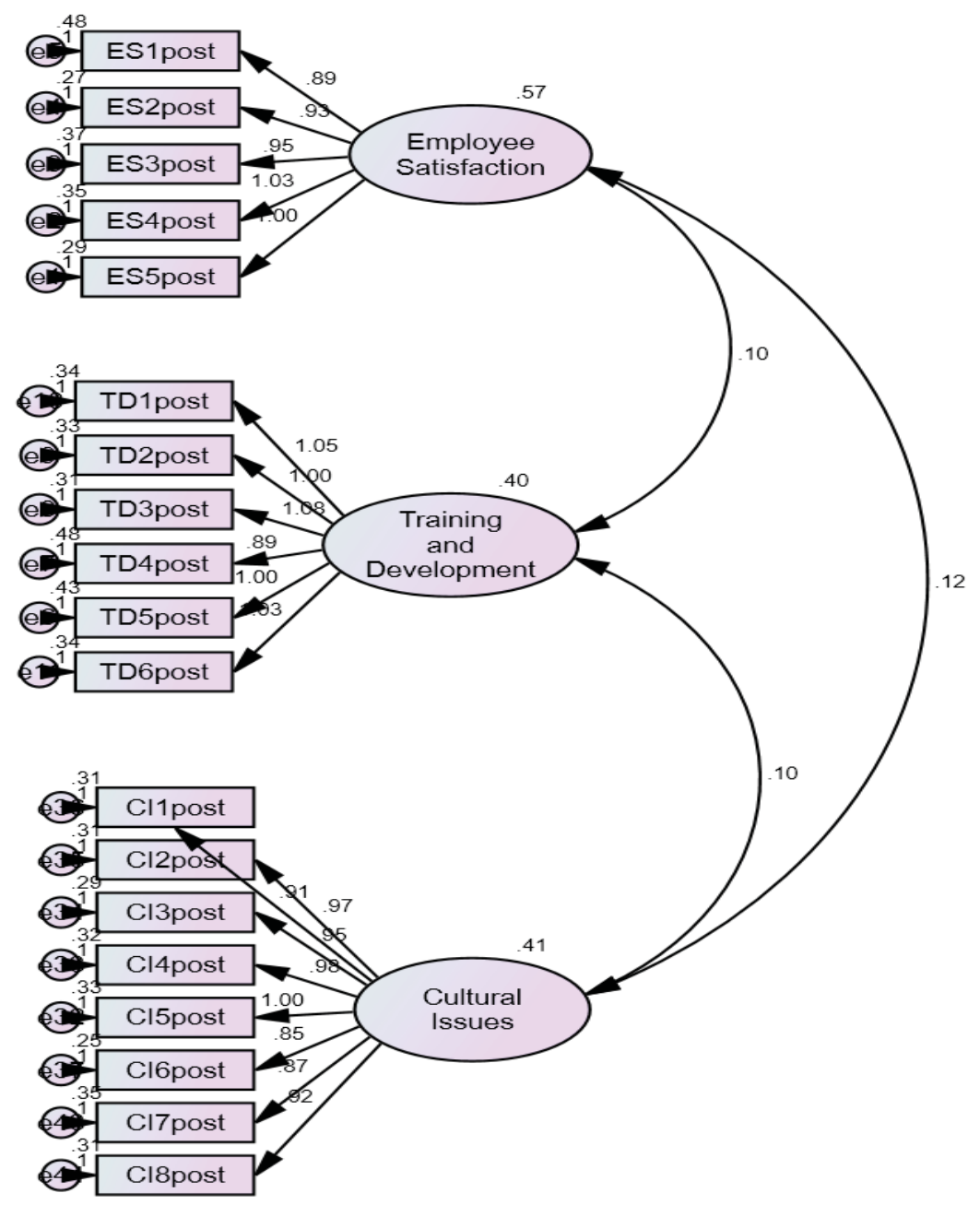

Figure 2: CFA of HR strategies 
Table 1 represents the convergent and discriminant validity by way of Composite Reliability (CR), Average Variance Extracted (AVE), Maximum
Shared Variance (MSV) and Average Shared Variance (ASV).

Table 1: Construct Validity Statistics

\begin{tabular}{|c|c|c|c|c|c|c|c|}
\hline & 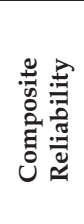 & 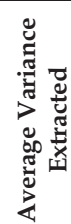 & 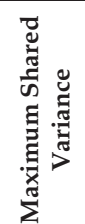 & 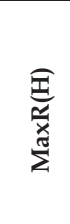 & 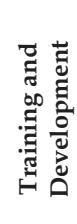 & 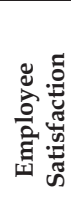 & 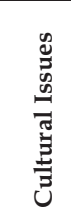 \\
\hline Training and Development & 0.870 & 0.528 & 0.062 & 0.874 & 0.727 & & \\
\hline Employee Satisfaction & 0.882 & 0.600 & 0.062 & 0.936 & 0.201 & 0.775 & \\
\hline Cultural Issues & 0.902 & 0.537 & 0.062 & 0.960 & 0.248 & 0.249 & 0.732 \\
\hline
\end{tabular}

The results of the construct validity indicated that the CR for all the constructs was more than 0.70 . Similarly, The AVE for all the constructs was also found to be more than 0.50 . Additionally, the results showed that CR> AVE. Thus, individual constructs were found to be valid, reliable and ensured the presence of convergent validity. While assessing discriminant validity the results showed that AVE > MSV and AVE $>$ ASV.

Table 2: Model fit indices

\begin{tabular}{|l|c|c|c|c|c|}
\hline Model Fitness Index & CMIN/DF & CFI & GFI & TLI & RMSEA \\
\hline Estimated Value & 1.639 & 0.974 & 0.940 & 0.970 & 0.040 \\
\hline
\end{tabular}

Thereafter, having checked the convergent and the discriminant validity of the measurement model, the fitness of the measurement model was tested. The model fit indices are depicted in the table 2. In order to ascertain whether the model fits the data, goodness of fit and badness of fit estimates of the model were verified using AMOS. The goodness of fit was represented by CMIN/ DF (the closer to degree of freedom the better it is considered) CFI (> $0.95)$, GFI $(>0.90)$ and TLI $(>0.90)$ values and badness of fit indices was shown by RMSEA ( $f$ 0.05) (Hair et al., 2006). Finally, the model yielded good model fit.

\section{Structural Equation Model (SEM)}

Structural Equation Modeling was conducted to examine the impact of Merger and Acquisition (M\&A) on HR strategies of the acquiring Indian firms. In the structural model M\&A was denoted as exogenous constructs which was related to three endogenous constructs;

- Employee Satisfaction,

- Training and Development

- Cultural Issues.

The superiority of relationship between the independent and the dependent variables were accessed by the values of path coefficients or the $\beta$ value. The path from M\& A to Employee Satisfaction $(\beta=0.316, t=6.612, p<0.05), M \& A$ to Training and Development $(\beta=0.232, t=5.381, p<0.05)$ and $M \& A$ to Cultural Issues $(\beta=0.293, t=7.106, p<0.05)$ were found to be significant, thus, supporting the hypothesis proposed in the study. Further, standard error of estimate (S.E.) computes the error of prediction. The values of S.E. for all the three paths are low, explaining minor error of prediction. Moreover, critical ratio (CR) is also significant as the values are higher than \pm 1.96 . Therefore, it can be 
assumed that at 95\% level of significance M\&A was significantly associated with HR strategies. Table 3 and figure 3 presents the detail summary of structural equation model.

Table 3: Details of SEM Results

\begin{tabular}{|c|c|c|c|c|c|c|c|c|}
\hline Endegeneous Construct & & $\begin{array}{c}\text { Exogeneous } \\
\text { Construct }\end{array}$ & \begin{tabular}{|l|} 
Standardized \\
Regression \\
Coefficient
\end{tabular} & $\begin{array}{c}\text { Unstandardized } \\
\text { Regression } \\
\text { Estimate }\end{array}$ & S.E. & C.R. & $\mathbf{P}$ & R Square \\
\hline Employee Satisfaction & $<--$ & \multirow{3}{*}{$\begin{array}{l}\text { Merger } \\
\text { Effects }\end{array}$} & 0.339 & .316 & .052 & 6.030 & $* * *$ & 0.14 \\
\hline Training and Development & $<--$ & & 0.297 & .232 & .045 & 5.123 & $* * *$ & 0.08 \\
\hline Cultural Issues & $<--$ & & 0.375 & .293 & .044 & 6.596 & $* * *$ & 0.11 \\
\hline
\end{tabular}

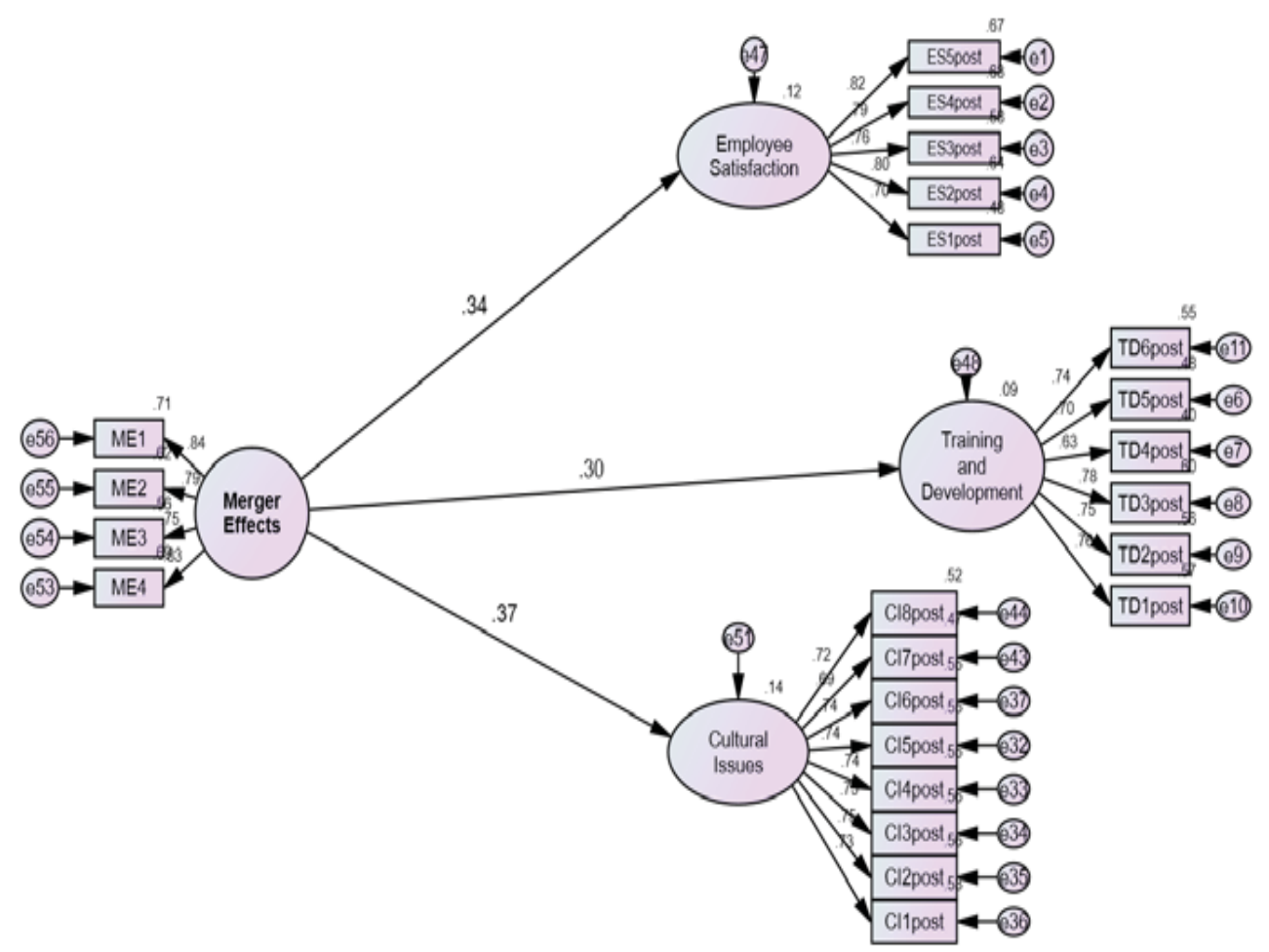

Figure 3: SEM Model

Thereafter, having checked the hypothesis of the study with the aid of the path coefficient value the fitness of the structural model was accessed. In order to ascertain whether the model fits the data, goodness of fit and badness of fit estimates of the model were verified using AMOS. The goodness of fit was represented by CMIN/ DF (the closer to degree of freedom the better it is considered) CFI (> $0.95)$, GFI $(>0.90)$ and TLI $(>0.90)$ values and badness of fit indices was shown by RMSEA $(\leq 0.05)$ (Hair et al., 2006). Finally, the model yielded good model fit. The model fit indices of the structural model are depicted in the table below-: 
Table 4: Structural Model Fit Indices

\begin{tabular}{|l|c|c|c|c|c|}
\hline Model Fitness Index & CMIN/DF & CFI & GFI & TLI & RMSEA \\
\hline Estimated Value & 1.514 & 0.974 & 0.930 & 0.971 & 0.036 \\
\hline
\end{tabular}

\section{Discussion and Conclusion}

The study was carried out to find the impact of merger and acquisition (M\&A) on human resource (HR) strategies. Previous studies have reflected relationship of the M\&A with the individual aspects of human resources strategies i.e. HR policies. The existing research work further examined M\&A in relation to HR outcomes and HR issues. This linkage has not been of use in understanding the goal of the HR concerned with M\&A. M\&A does not show the basic benefits gained by the human resources of the organization in terms of their performance and on the overall performance of the organization. The present study is aimed to take an integrated view of HR aspects like employee satisfaction, (HR outcomes), training \& development, (HR policies) and cultural issues (HR issues) under the concept of HR strategies and examine the impact of merger and acquisition on the strategies implemented by the HR.

Further as per the broad hypothesis, the study found that there is a significant impact of an M\&A on the HR Strategies of the acquiring firm. The $\beta$ value determined from the statistical results of the individual parameters of HR strategies were:

M \& A to Employee Satisfaction $(\beta=0.316, t=6.612$, $\mathrm{p}<0.05)$,

M \& A to Training and Development $(\beta=0.232, t=$ 5.381, $\mathrm{p}<0.05)$ and

M \&A to Cultural Issues $(\beta=0.293, t=7.106, p<0.05)$

These values were found to be significant, therefore supporting the hypothesis put forward in the study. The results of this study claim that M\& A have a significant and a positive impact on the HR practices of the acquiring firms. It was also evident from the results of the study that M\&A create a serious problem of cultural issues in the environment of the acquiring firms.
According to the present study, the HR managers of the Indian IT firms must ensure effective HR strategies post M\&A to add to the sustainable performance of the organization.

Thus, the results of the present study suggest that the HR leaders of the concerned organization must continuously and clearly redefine its HR policies post M\&A in order to bring subsequent implications on HR outcomes and issues. Furthermore, this will assist in enhancement of the M\&A performance of the acquiring firm in association with its financial gains, innovation of new products and in cutting down of research and development costs and finally expedite growth.

In conclusion, the impact of M\& A on HR strategies ie. HR policies \& HR practices resulted into significant changes in HR outcomes and HR issues which had indeed been acknowledged in the past literatures deriving similar results. It is with this notion that this research was conducted to examine the impact of M\&A on HR strategies. Hence the contribution of this research is that it provides insight on how M\&A can impact HR strategies in Indian IT firms.

\section{REFERENCES}

1) Allen, D. (2007). Strategic acquisition amid business unscertainty: Charting course for your company M\&A. Deloitte Research-Economist Intelligence Unit M\& A Survey, 1-12.

2) Appelbaum, S. H., Gandell, J., Yortis, H., Proper, S., \& Jobin, F. (2000). Anatomy of a merger: Behavior of organizational factors and processes throughout the pre-during-post-stages (part 1). Management Decision, 38(9), 649-662.

3) Armstrong, M. (2016). Armstrong's handbook of strategic human resource management, London: Kogan Page. 
4) Armstrong, M., \& Stephens, T. (2005). A handbook of management and leadership: A guide to managing for results, London: Kogan Page Limited.

5) Armstrong, M., \& Taylor, S. (2015). Armstrong's handbook of human resource management practice, London: Kogan Page.

6) Armstrong, M., \& Baron, A. (2002). Strategic HRM, the key to improved business performance, London: CIPD.

7) Baker, S. (2009). An examination of bank employees' job satisfaction after a merger and acquisition. PhD. Dissertation, North central University, United States-Arizona. Publication.

8) Bari, M. W., Fanchen, M., \& Baloch, M. A. (2016). Management practices and performance of mergers and acquisitions in Pakistan: Mediating role of psychological contract. SpringerPlus, 5(1), 1527.

9) Batt R. (2000). Strategic segmentation in frontline services: Matching customers, employees, and human resource systems. International Journal of Human Resource Management 11, 540-561.

10) Becker, B. E., Huselid, M. A., Pickus, P. S., \& Spratt, M. F. (1997). HR as a source of shareholder value: Research and recommendations. Human Resource Management, 36(1), 39-47.

11) Berger, R. (2009). www.rolandberger.com /media/pdf/Roland-Berger-Restructuring.

12) Buono, A.R., Bowditch, J. L., \& Lewis, J. W. (1985). When cultures collide: The anatomy of a merger. Human Relations, 38, 477-500. University of Ghana http:/ / ugspace.ug.edu.gh.

13) Bysted, R. \& Jespersen, K. (2013). Exploring Managerial mechanism that influence innovative work behaviour: Comparing private and public employees. Public Management Review, 16(2), 217- 241.

14) Caetano, A., \& Neves, P. (2006). Social exchange processes in organizational change: The roles of trust and control. Journal of Change Management, 6 (4), 351-364.

15) Clarke, N., \& Salleh, N. M. (2011). Emotions and their management during a merger in Brunei. Human Resource Development International, 14(3), 291-304.

16) Covin, T. J., Sightler, K. W., Kolenko, T. A., \& Tudor, R. K. (1996). An investigation of postacquisition satisfaction with the merger. The Journal of Applied Behavioral Science, 32(2), 125-142.

17) DeCenzo, D.A. \& Robbins, S.P. (1996). Personnel/ Human resource Management. (3rd Ed). New Delhi: Prentice-Hall of India Pvt. Ltd.

18) Delery, J., \& Doty, H. (1996). Modes of theorizing in strategic human resource management: Tests of universalistic, contingency, and configurational performance predictions. Academy of Management Journal, 39(4), 802835.

19) Ernst \& Young (2013).www.ey.com/...role-ofhr...practices/.../EY-Role-of-HR-in-drivingsustainable-busines. Accessed on 20 April 2018.

20) European Monitoring Centre on Change (2011). European Restructuring Monitor. Available from:www.eurofound.europa.eu/emcc/index.ht $\mathrm{m}$.

21) Fischer, P., Greitemeyer, T., Omay, S.I., Frey, D. (2007). Mergers and group status: The impact of high, low and equal group status on identification and satisfaction with a company merger, experienced controllability, group identity and group cohesion. Journal of Community and Applied Social Psychology, 17(3), 203-217.

22) Garcia, M. (2005). Training and business performance: The Spanish case, International Journal of Human arcia, M. (2005). Training and business performance: The Spanish case, International Journal of Human Resource

23) Garcia, M. U. (2005) Training and business performance: The Spanish case. The International Journal of Human Resource Management, 16(9), 1691-1710.

24) Goyal, K. A., \& Joshi, V. (2012) Impact of merger on stress level of employees (A case study of Erstwhile Bank of Rajasthan Ltd.). International Journal of Business Research and Management, 
3(5), 234-248.

25) Guthrie, J. P. (2001). High-involvement work practices, turnover, and productivity: Evidence from New Zealand. Academy of management Journal, 44(1), 180-190.

26) Hair, Joseph F., William C. Black, Barry J. Babin, Rolph E. Anderson, and Ronald L. Tatham. "Multivariate data analysis (Vol. 6)." (2006): 289.

27) Hair, Jr. J.F., Anderson, R.E., Tatham, R.L., \& Black, W.C. (1998). Multivariate data analysis. New Jersey: Prentice-Hall.

28) Harel, G. H., \& Tzafrir, S. S. (1999) The effect of human resource management practices on the perceptions of organizational and market performance of the firm. Human Resource Management: Published in Cooperation with the School of Business Administration, The University of Michigan and in alliance with the Society of Human Resources Management, 38(3), 185-199.

29) Hirsch, P. \& Sourcey, M. (2006) Organizational Restructuring and its Consequences - Rhetorical and Structural. Annual Review of Sociology, 32, 171-189.

30) Hogan, E. A., \& Overmyer-Day, L. (1994) The psychology of mergers and acquisitions. International review of industrial and organizational psychology, 9, 247-247.

31) Islam S, Sengupta P.P, Ghosh S, Saha M and Basu S.C. (2012), The behavioural aspect of mergers and acquisitions: A case study from India. Global Journal of Business Research, 6 (3), 103-112.

32) Jørgensen, V. B., \& Jørgensen, I. B. (2010). The importance of mergers \& acquisitions within the Danish banking sector during a financial crisis. Business Administration and International Management.

33) Kieselbach, T. (2009). Health in restructuring: Innovative approaches and policy recommendations. Rainer Hampp Verlag.

34) Knol, J. \& van Linge, R. (2009) Innovative behaviour: the effect of structural and psychological empowerment on nurses. Journal of Advanced Nursing, 65(2), 359-370.
35) Liu, Y., Sarala, R. M., Xing, Y., \& Cooper, S. C. L. (2017). Human side of collaborative partnerships: A microfoundational perspective. Group \& Organization Management, 42(2), 151-162.

36) Management, Vol.16, pp.1691-1710

37) Meyer, J. P., \& Allen, N. J. (1997). Commitment in the workplace: theory, research, and application (Advanced Topics in Organizational Behavior). Thousand Oaks, CA: Sage Publications.

38) Newman, J. M., \& Krzystofiak, F. J. (1993). Changes in employee attitudes after an acquisition: A longitudinal analysis. Group \& Organization Management,18 (4), 390-410.

39) Nikandrou, I., Papalexandris, N., \&Dimitris, B. (2000) Gaining employee trust after acquisition and merger: Implications for managerial action. Employee Relations, 22 (4) , 334-347.

40) Obeidat, B. Y., \& Abdallah, A. B. (2014) The relationships among human resource management practices, organizational commitment, and knowledge management processes: A structural equation modeling approach. International Journal of Business and Management, 9 (3), 9.

41) Ostroff, C., \& Bowen, D. (2000). Moving HR to a higher level: HR practices and organizational effectiveness. In K. Klein \& S. Kozlowski (Eds.). Multilevel theory, research, and methods in organizations: Foundations, extentions, and new direction, 211-266. San Francisco: Jossey Bass.

42) Probst, T. M. (2003). Exploring employee outcomes of organizational restructuring: A Solomon four-group study. Group \& Organization Management, 28(3), 416-439.

43) Purcell, J. (1989).The impact of corporate strategy on human resource management. New Perspectives on Human Resource Management, J. Storey. (Ed) London: Routledge.

44) Raquib, M. P.B. \& Mohamed, M. B. (2003). Strategic issues relating to corporate mergers and acquisition for small and medium companies-A thoughtful analysis from the viewpoint of challenges of change. Asia Pacific 
Management Review, 8 (1), 99-112.

45) Rashid, A. \& Naeem, N. (2017). Effects of mergers on corporate performance: An empirical evaluation using OLS and the empirical Bayesian methods. Borsa Istanbul Review, 17 (1), 10-24.

46) Roberts, P. A., Wallace, D. W. \& Moles, D. P. (2003). Mergers and Acquisitions .Edinburgh.

47) Sanda, M.A.\& Adjei-Benin, P. (2011). How is the firm dealing with the merger? A study of employee satisfaction with the change process. Journal of Management and Strategy, 2 (2), 2837.

48) Schoenberg, R. (2006). Measuring the performance of corporate acquisitions: An empirical comparison of alternative metrics. British Journal of Management, 17(4), 361-370.

49) Sharma, V. \& Mareja, N. (2016). A study on role of human resource post acquisition: a case study of sun pharmaceuticals and ranbaxy laboratories.Clear International Journal of Research in Commerce \& Management, 7(9).

50) SHRM

https://www.shrm.org/resourcesandtools/tool s-and samples/toolkits/pages/ mergersandacquisitions.aspx. Accessed on 16 th April, 2018.

51) Spiegelaere, S., de, Van Guys, G. \& Van Hootegem, G. (2012). Job design and innovative work behavior: One size does not fit all types of employees. Journal of Entrepreneurship, Management and Innovation, 4, 5-20.

52) Storrie, D. \& Ward, T. (2007). ERM Report 2007. Restructuring and employment in the EU: The impact of globalization: Evidence of offshoring in the European Restructuring Monitor. Dublin (Ireland).

53) Thang, N. N., \& Buyens, D. (2008). What we know about relationship between training and firm performance: A review of literature. In 7th International Conference on Ethics and Quality of Work-life for Sustainable Development, Bangkok, Thailand.

54) Thang, N. N., \& Buyens, D. (2009). What we know about the relationship between training and firm performance.

55) Tsui, A., Pearce, J., Porter, L., \& Tripoli, A. (1997). Alternative approaches to the employeeorganization relationship: Does investment in employees pay off? The Academy of Management Journal, 40(5), 1089-1121.

56) Vandenberg, R., \& Nelson, J. (1999). Disaggregating the motives underlying turnover intentions: When do intentions predict turnover behavior? Human Relations, 52(10), 1313-1336.

57) Vidija, S. E., Peter, K., \& Ogutu, M. (2016). Human resource management practices and performance of firms listed on the Nairobi securities exchange. Journal of Human Resource and Leadership, 1 (1), 1-24.

58) Weber, Y., Rachman-Moore, D., \& Tarba, S. Y. (2012). HR practices during post-merger conflict and merger performance. International Journal of Cross Cultural Management, 12(1), 73-99.

59) Woodward, C. A., Shannon, H.S., Cunningham, C.E., McIntosh, J.E., Lendrum, B., Rosenbloom, D., \& Brown, J. (1999) The impact of reengineering and other cost-reduction strategies on staff of a large teaching hospital: A longitudinal Study. Medical Care, 37, 547-555.

60) Yu, J., Engleman, R. M., \& Van de Ven, A. H. (2005) The integration journey: An attentionbased view of the merger and acquisition integration process. Organization Studies 26(10), 1501-1528. 